\title{
A modernidade chega de trem: a inauguração da ferrovia em Campinas, São Paulo, em 1872
}

Modernity arrives by train: the opening of the railroad in Campinas, São Paulo, in

Doutorando em História na Universidade do Minho, Portugal guipozzer@yahoo.com.br

Resumo: Este trabalho analisa o modo como a chegada da ferrovia em Campinas, São Paulo, representou os anseios e valores da modernidade do século XIX. Para isso, a pesquisa é inserida no debate em torno da questão da modernidade e do emprego desse conceito para compreensão do objeto de estudo. O levantamento da documentação sobre a abertura do tráfego ferroviário em Campinas no ano de 1872 busca entender a articulação desse sistema de transporte com o tecido urbano no seu aspecto social e cultural, bem como os anseios da cidade em relação a sua implantação e os múltiplos significados em torno daquele evento.

Palavras Chaves: Ferrovias, narrativas da modernidade, Campinas (São Paulo, Brasil).

\begin{abstract}
This paper examines how the arrival of the railroad in Campinas, São Paulo, represented the aspirations and values of modernity of the nineteenth century. For that purpose, the research is linked to the debate around the question of modernity and to the use of this concept for understanding the subject matter. The documentation survey on the opening of railway traffic in Campinas in 1872 seeks to understand the articulation of this transportation system with the urban tissue in its social and cultural aspects as well as the city's aspirations with regard to its implementation and multiple meanings.
\end{abstract}

Keywords: Railroads, narratives of modernity, Campinas (São Paulo, Brazil). 


\section{Modernidade e ferrovia}

A natureza dos fenômenos que se desenvolviam no interior das cidades no século XIX era totalmente nova, com "a multidão dos habitantes, o número de novas casas, a capacidade das novas zonas industriais e comerciais, os quilômetros de novas estradas e canais, o número de veículos que circulam nas estradas" (BENEVOLO, 1989: 20). Esse conjunto de transformações originou mudanças nos modos de vida, modificou a utilização do solo e a própria paisagem.

Hardman afirma que o século XIX expressou múltiplas reações “entre indignação, espanto e encantamento" ante aquelas transformações:

No vasto e intrincado painel que se desenhava em torno das novas relações entre técnica e sociedade, os efeitos de uma ilusão óptica generalizada percorriam povos e países, dominavam o olhar das multidões, faziam-se sentir nos veios recônditos do planeta (HARDMAN, 1988: 24).

Por todos os lugares em que passou, a ferrovia aparece como um dos maiores símbolos de progresso, civilização, modernização e modernidade (HARDMAN, 1988; LESSA,1993). Modernidade essa que

se vislumbrava pelas novas ideias em voga e, por uma série de inventos que mudaram o ritmo das capitais do mundo na segunda metade do século XIX. O deslumbramento com as novas tecnologias: o transporte ferroviário que deslocava mais rapidamente homens e mercadorias, o telefone que revolucionou as comunicações nas cidades e, a fotografia que registrava imagens com velocidade e precisão, o debate em torno das raças e sociedades humanas, o racismo científico, o evolucionismo. Toda essa carga de novas técnicas e novos conceitos fascinava o homem e criava um otimismo na capacidade de superação humana (CUNHA, 2010).

Para Lapa, existem

certas palavras que exercem um fascínio por parecerem conter a capacidade de idealizar e representar a realidade de uma maneira mais acabada. (...) Modernos, modernidade, modernismo e modernização estão nesse caso e têm 
uma identidade que não impede as diferenças e especificidades que também guardam entre si (1996: 18).

Ao analisar os termos moderno, modernização e modernidade, Jacques Le Goff salienta as diferenças entre cada um e mostra que seus usos dizem respeito a situações diversas, principalmente após o advento da industrialização (1990: 169, 179). Movimentos de ordem literária, artística e religiosa são chamados ou assumem-se como modernistas; a modernização poderia se dar no campo da economia, da técnica, mas também no âmbito social e cultural, o que se verificou no choque entre "países desenvolvidos" e "atrasados"; por último, ligado à aceleração na produção cultural no ocidente, se consolida no campo da criação estética, das mentalidades e dos costumes o conceito de modernidade, e a consciência sobre essa última nasceria do sentimento de ruptura com o passado.

Segundo Marshall Berman, a modernização seria fruto do processo econômico, o modernismo fruto da experiência cultural, e a modernidade se encontraria entre esses dois processos, funcionando como uma ligação, como "um tipo de experiência vital" compartilhada por homens e mulheres em todo o mundo" (1982: 15)1.

Assim, modernização e modernidade designam as transformações da relação do homem com a natureza, seja ela original ou já transformada por sua ação; uma mudança nas relações dos homens entre si, se não superando antigos hábitos e tradições, ao menos questionando-os. Ocorreria, então, uma modificação no modo de pensar a relação do homem com a própria realidade que o cerca, no sentido de superar tudo aquilo que não poderia ser considerado urbano, civilizado e compatível com a ideia de progresso, como "sinônimo de desenvolvimento, que só se atinge transformando a vida social, para melhorá-la" (LAPA, 1996: 18).

Nesse sentido, a experiência da modernidade no século XIX terá como palco principal as áreas urbanas.

a primeira coisa que observaremos será a nova paisagem, altamente desenvolvida, diferenciada e dinâmica, na qual tem lugar a experiência moderna. Trata-se de uma paisagem de engenhos a vapor, fábricas

\footnotetext{
${ }^{1}$ Observa-se que, para Berman, tal experiência, no entanto, teria uma contradição intrínseca, porque ao mesmo tempo em que permite a construção de perspectivas positivas sobre a realidade ela "ameaça destruir tudo o que temos, tudo o que sabemos, tudo o que somos" (1982: 15).
} 
automatizadas, ferrovias, amplas novas zonas industriais; prolíficas cidades que cresceram do dia para a noite (BERMAN, 1982: 18-19).

Em tal processo, destacam-se as ferrovias, pois as cidades por onde passavam eram inevitavelmente modificadas (GRAHAM, 1973: 124). As ferrovias funcionaram como estímulo ao processo de aglomeração urbana, porque muitas vezes foi

em função da nova rede de transportes e do movimento comercial sempre em expansão que convém interpretar o crescimento sem precedentes de algumas cidades, para onde convergiam as vias comerciais e onde se encontravam as alavancas de comando, financeiras e administrativas (BENEVOLO, 1994: 20).

Hobsbawm afirma que, para os países latino-americanos, o crescimento econômico da Europa, na segunda metade do século XIX, teria fortalecido as minorias detentoras do poder, “devotadas à modernização do continente” (1996: 177). Impostas por uma elite culta e urbana em um continente rural, as ideologias do "progresso" envolviam a América Latina, de modo que se teria tentado transformar a sociedade por meio da modernização institucional imposta pelo poder político, o que fracassaria pelo fato de não existir independência econômica. ${ }^{2}$

Segundo esse argumento, para que os modelos de modernidade e de modernização europeus pudessem ser implantados em quaisquer outras partes do globo as bases ideológicas e as estruturas materiais deveriam estar consolidadas para se desenvolver, e os países que não possuíssem tais bases são considerados explorados ou perdedores. Neste sentido, Emília Viotti da Costa (1979: 179) afirma que a sobrevivência de estruturas de produção colonial no Brasil, mesmo depois da independência, foi responsável por transformações que fugiram aos padrões "clássicos", fundados nas áreas centrais do sistema capitalista.

\footnotetext{
${ }^{2}$ Dependência econômica essa que, como afirma Paul Singer (1998), era "consentida" ao longo do século XIX até a Primeira Guerra Mundial e caracterizada "pela ausência de qualquer dinâmica interna capaz de impulsionar o desenvolvimento". Em locais onde o território era vasto, como é o caso do Brasil, era premente sua unificação por meio de ferrovias e hidrovias, sendo, portanto, imperativo "importar equipamento, know-how e componentes". Porém, implementar tais serviços era possível somente nas áreas em que "a produção para o mercado externo proporcionava um excedente monetário". Fosse público ou privado, as melhorias infraestruturais dependiam "diretamente do que cada região do país conseguia colocar no mercado mundial. Esta realidade era compreendida e aceita pelo conjunto da sociedade" (SINGER, 1998: 120).
} 
Para Ádrian Gorelik (1999: 59), na América a modernidade foi um caminho para chegar à modernização, não sua consequência; a modernidade se impôs como parte de uma política deliberada para conduzir à modernização, de modo a apresentar uma vontade ideológica para produzir um determinado tipo de transformação cultural. Assim, ocorreria que muitas vezes as ideias e os climas culturais "viajariam" mais rápidos que os objetos e processos a que se referem, havendo certo desajuste em relação ao modelo, cujos resultados seriam originais e específicos.

Segundo Cunha, "modernidade era a palavra de ordem, aqueles que representavam social e politicamente a sociedade europeia e suas sociedades satélites usavam com frequência esse termo, como promessa para os países periféricos e realidade para as nações prósperas da Europa" (2010: 29).

Francisco Foot Hardman trata esse contexto como sendo um movimento simultâneo e internacional de constituição das sociedades produtoras de mercadorias, e a entrada do Brasil o inscrevia na ótica moderna do exibicionismo burguês (1988: 16, 68).

Em consonância com essa visão, ao comentar a análise de Le Goff (1990), Lapa afirma que a modernidade é "criação eminentemente cultural e burguesa, gerada no ventre da Revolução Industrial, identifica valores, estilos, maneiras de ser” (1996: 18) paradoxais no ocidente.

Em Campinas, esse paradoxo da modernidade pode ser sentido, por exemplo, nas condições sociais da cidade na segunda metade do século XIX, uma vez que, segundo Lapa, seja importada ou até produzida pela cidade, a modernidade guarda um conflito entre sua estrutura social e econômica: a cidade apresentava uma sociedade agrária e escravista, dominada por uma aristocracia aspirante à urbanidade, mas que privilegiava $\mathrm{e}$ cultuava valores de uma "burguesia industrial e industriosa" (LAPA, 1996: 18).

Lapa entende a modernidade

em correspondência com aquela racionalidade burguesa que se estende pelo econômico, pelo social, pelo político e pelo cultural, atingindo as mentalidades, os costumes e a criação estética, não necessariamente nessa ordem, com o atraso que se espera para um país do Terceiro Mundo e com as especificidades que uma sociedade escravista conserva (1996: 19).

Neste sentido, o ideal de modernidade representaria uma ruptura com o passado (LE GOFF, 1990: 169; KUMAR, 1997: 97), de modo que, embora as condições sociais, 
políticas e econômicas em Campinas fossem divergentes das que proporcionaram o surgimento deste ideal na Europa no século XIX, o fato de ela estar sendo apropriada pela sociedade local representou uma nova maneira de encarar o presente e o futuro precisamente ao questionar o passado por meio das transformações urbanas que ocorriam na cidade.

Assim, se por um lado, a Europa constituía um modelo a ser seguido tanto em termos de modernização quanto de modernidade, de outro lado, porém, não se pode pensar que haveria sua simples cópia, mas, sim, uma assimilação de valores a partir das possibilidades e necessidades específicas do país, cujas referências eram claramente europeias, das quais a ferrovia era um dos maiores representantes desse modelo.

\section{Campinas à espera do trem: expectativa na cidade em torno da ferrovia}

Meses antes da inauguração da ferrovia entre Jundiaí e Campinas, o relato de um viajante, J. Van Halle, publicado na Gazeta de Campinas em 6 de janeiro de 1872, chamava a atenção por demonstrar os problemas da estrada que ligava essas duas cidades $(1872) .^{3}$

Até Jundiaí Van Halle percorreu o trajeto de trem pela São Paulo Railway e, depois de deixar a ferrovia, tomou

uma espécie de carruagem (trole) puxada por quatro mulas (...) pela única estrada pública que vai a Campinas.

Lama e lagoa a inundarem o caminho; (...) pontes quebradas (...). Por duas vezes o nosso pobre veículo atolou-se quase completamente (...). Mais tarde e apenas a três léguas da cidade, nosso trole virou em um morro, e eis-nos, viajantes de ambos os sexos, cocheiros, bestas, malas, armas e bagagens precipitados em confusão na água e na lama! (HALLE, 1872: 2).

Van Halle apontou a precariedade da estrada entre Jundiaí e Campinas, enfatizou o fato de ela ser a única via pública entre essas duas cidades - o que tornava a péssima conservação em que se encontrava ainda mais grave - e mostrou as situações "inusitadas" a que eram submetidos os que faziam essa travessia (HALLE, 1872: 2).

\footnotetext{
${ }^{3}$ O relato é parte de alguns artigos que ele escreve para a Gazeta de Campinas, intitulados "Impressões de minha viagem ao Brasil - Progressus - Indústria - Veritas". O que se menciona tem como subtítulo "Viagem de São Paulo a Campinas" (Halle, 1872; 2).
} 
O relato de Van Halle chama a atenção por abordar questões de grande interesse na época, a partir das situações por ele vividas no percurso entre Jundiaí e Campinas. Suas críticas às condições das estradas públicas, entretanto, não eram isoladas. Como mencionado, esse foi um tema recorrente e recebeu destaque desde o primeiro ano da Gazeta de Campinas (1868).

O "tom” dado às discussões sobre as estradas e as condições do transporte no país passava ao público leitor a ideia de que a vinda da ferrovia para a cidade não se tratava de um substituto às possibilidades de transporte já existentes, mas de um complemento que representava um passo a mais rumo à modernização dos transportes.

Embora as motivações fossem de ordem material, elas são buscadas também por serem referências de valores a serem perseguidos. Assim, tal modernização, com a mudança nos transportes proporcionada pela ferrovia, entretanto, não ocorreu apenas em termos econômicos, mas também em termos de percepções da natureza e de mundo.

Hardman ressalta, nesse sentido, o "poder transfigurador da locomotiva, os efeitos da velocidade sobre a percepção espaço-temporal, o deslocamento rápido propiciado pela força do maquinismo, alterando a visão da paisagem e dos passantes" (1988: 24). Furtado (1998: 34) e Schivelbusch (1986: 11-12) mostram de forma semelhante que, ao ser inserida no cotidiano, a ferrovia e as próprias características do ambiente mecânico proporcionaram novas formas de percepção da realidade, especialmente quanto à relação do homem com o tempo e o espaço.

Desta maneira, tais transformações modificaram a relação do homem com a natureza e trouxeram, segundo Lessa, uma "perda da relação sensorial", da "relação mimética" com o meio (1993: 23-24).

A estrada de ferro surgiu em todos os locais pelos quais passou como elemento simbólico de "desbravador de espaços", do domínio do homem sobre a natureza, dos prodígios científicos e das trocas culturais que ela proporcionava. E em Campinas, dias antes da inauguração da linha até Jundiaí, a expectativa quanto à abertura do tráfego valorizava exatamente esse papel da estrada de ferro:

(...) e quando invade o deserto, quebra-lhe o silêncio; dá fertilidade a áridas terras; alegra a sombria solidão das florestas gigantescas e seculares, (...) funda núcleos de população, anima o trabalho, lança o gérmen de civilização. Prodigioso invento do século científico, em que vivemos, as estradas de ferro recordando sempre a Vitoria e o domínio da inteligência sobre as forças 
materiais pressagiam e facilitam as trocas das ideias, pelo estreitamento das relações, pela vulgarização das ciências, das artes, e de tantas outras condições de aperfeiçoamento social (A. B., 1872: 1).

Depois, na edição do dia da inauguração da ferrovia, a Gazeta de Campinas exaltava a máquina a vapor, que "não somente mata a distância: ela destrói os preconceitos, a rotina, os velhos e maus hábitos" (SANTOS, 1872a: 2).

Desse modo, a ferrovia não era apenas representativa de progresso material, mas também da possibilidade de trazer a Campinas valores ligados à noção de progresso e civilização então existentes, de cosmopolitismo, o que propiciaria "intercâmbios culturais", romperia quaisquer barreiras entre os homens e traria um futuro de prosperidade por onde quer que seus trilhos passassem.

É com grande nitidez que se percebe a expectativa gerada na cidade pela vinda da ferrovia. A estação já servia como referência antes mesmo do início do tráfego entre Jundiaí e Campinas, como mostram alguns anúncios comerciais nos jornais. No que diz respeito a essa expectativa, uma imagem anterior ao tráfego ferroviário se constitui simbólica: a ilustração acompanha anúncio da casa comercial "Ferreira Novo \& Filho", que trazia diversos artigos da corte, como um "grandioso sortimento de fazendas, ferragens, louças e molhados, sendo a maior parte vindo por encomenda das principais fábricas da Europa" (ANÚNCIO, 1872: 4).

\section{Imagem 1}

Anúncio da casa comercial "Ferreira Novo \& Filho".

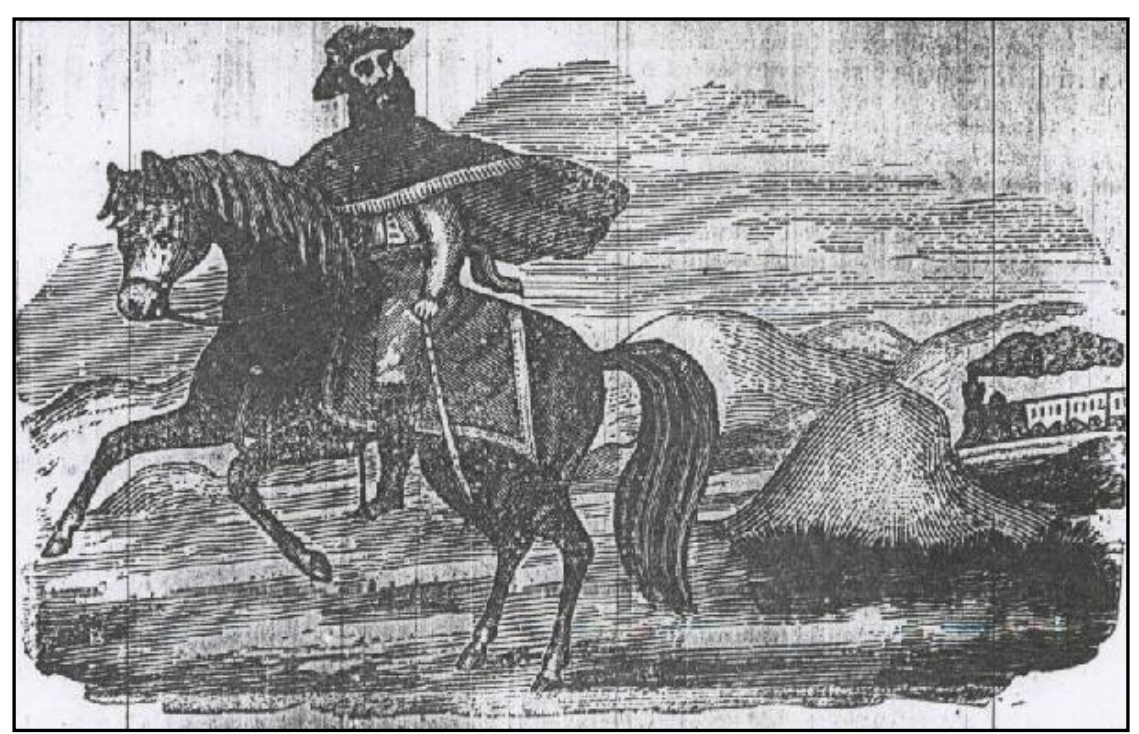

Fonte: $A N U ́ N C I O, 1872: 4$. 
$\mathrm{Na}$ imagem observa-se um cavaleiro, ou um tropeiro, que olha ao longe uma locomotiva e seus vagões. Nota-se que tanto a locomotiva quanto o tropeiro estão voltados para o mesmo sentido.

Ao se pensar na imagem como ilustração de uma propaganda, o mais lógico é que ela servisse de apologia ao que estava sendo "propagandeado", no caso o estabelecimento comercial. Pelo sentido em que estão posicionados o tropeiro e locomotiva, aquele se encontra à frente. Assim, a imagem vinculada à propaganda da casa de comércio poderia traduzir a permanência da utilização do antigo meio de transporte na busca de seus produtos na corte, evidenciando a tentativa de manter a "tradição" do estabelecimento em meio ao período de transformação. No entanto, a imagem também serve ao propósito comercial ao evidenciar que a ferrovia seria a grande responsável pela possibilidade de se adquirir produtos que vinham da Europa, tão "modernos" quanto a própria máquina ferroviária que os transportaria.

Nesse sentido, traçar um paralelo entre a imagem e o momento pelo qual Campinas passava permite interpretar as duas figuras presentes como metáforas de uma cidade que ainda era possuidora de valores tradicionais e que contemplava a chegada rápida do progresso, que consigo trazia transformações, diretas ou não, à vida de todos, em termos materiais e culturais.

Ao se separar em três os personagens presentes na imagem - o cavalo, o animal; a locomotiva, a máquina; e o homem, vestido como alguém do meio rural, ou apenas não urbano -, pode-se tomá-la como a contemplação do advento tecnológico pelo homem que monta o cavalo, não passando despercebido o seu olhar de espanto perante a máquina que supera em muitos Horse-Power sua montaria, até então o meio de transporte mais eficaz e veloz.

Ainda que não se possam precisar objetivamente as intenções contidas na imagem, ela traduz e condensa em si um sentimento de expectativa quanto à chegada do trem e de todas as mudanças que este proporcionaria à vida urbana e da carga simbólica que ele trazia consigo. Expectativa essa que era traduzida em jornais e, posteriormente, nos almanaques da cidade, onde se podia acompanhar as fases de construção da estrada de ferro e as projeções sobre a conclusão do trajeto entre Jundiaí e Campinas. 


\section{Os preparativos para a festas}

A montagem da estrutura ferroviária entre Jundiaí e Campinas exigiu a aquisição de terrenos e acordos entre a Companhia Paulista, particulares e com a Câmara Municipal, além da preparação da área em torno da estação ferroviária ao trânsito daqueles que utilizariam os seus serviços.

De todo modo, ao término dos trabalhos, pôde-se realizar a esperada inauguração, evento para o qual houve grande preparação da cidade, com decoração e reorganização do tráfego nas ruas, atos simbólicos para receber a ferrovia, jantares e reuniões com a presença de acionistas e representantes do poder público local.

\section{Imagem 2}

Convite para a inauguração da estrada de ferro em Campinas.

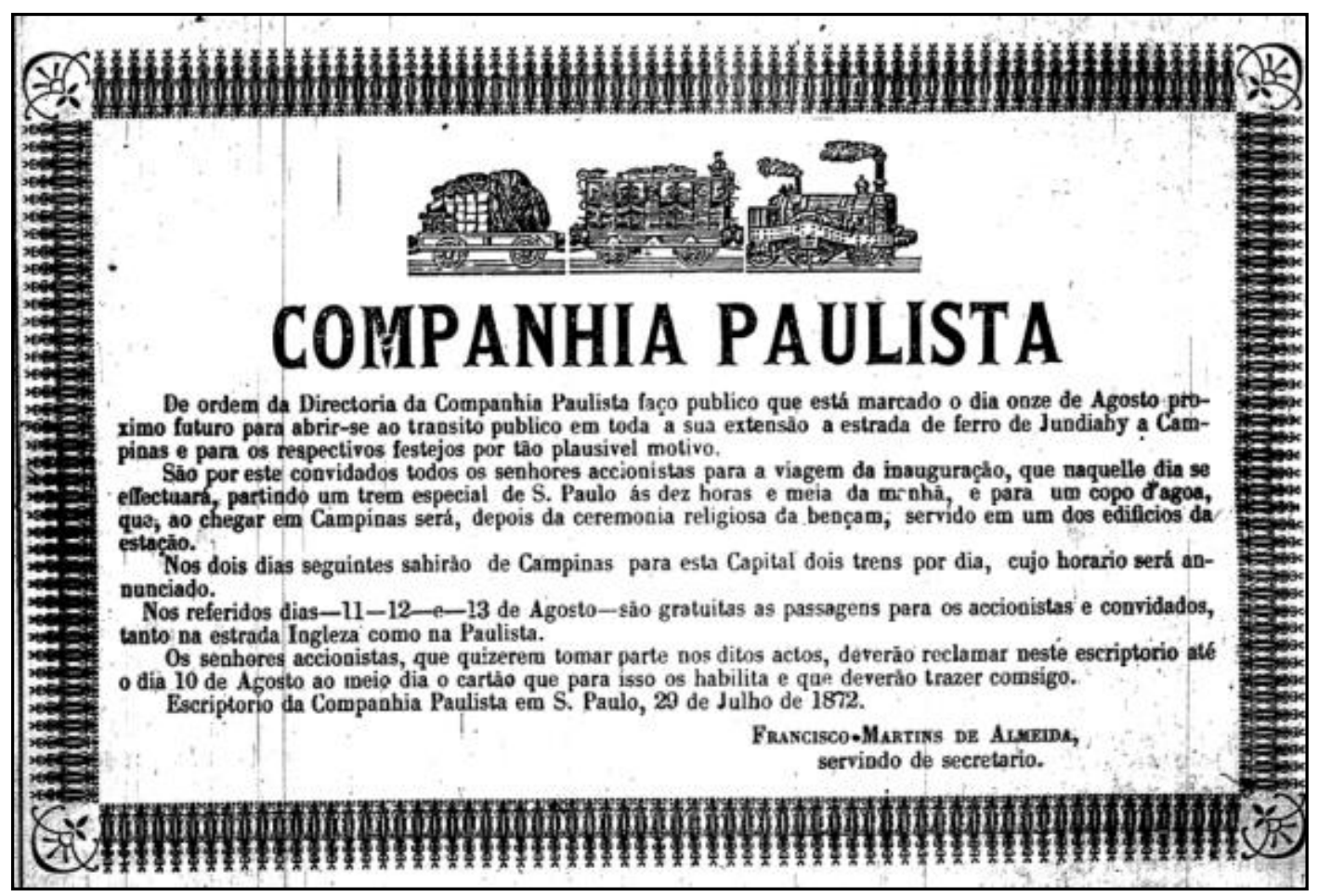

Fonte: COMPANHIA PAULISTA, 1872: 2.

A Gazeta de Campinas, em $1^{\circ}$ de agosto, publicou o convite aos acionistas para que comparecessem ao evento. Como se vê na imagem 2, circundada com enfeites, a caixa de texto apresentava a imagem de uma locomotiva e dois vagões, o primeiro de passageiro e o segundo de carga, e em letras maiúsculas o texto "Companhia Paulista", de modo a destacá-lo na edição do jornal. O convite se estendia a 
todos os senhores acionistas para a viagem de inauguração, que naquele dia [11 de agosto] se efetuará, partindo um trem especial de S. Paulo às dez horas e meia da manhã, e para um copo d'água, que, ao chegar em Campinas será, depois da cerimônia religiosa da benção, servido em um dos edifícios da estação. (...) Nos referidos dias - $11-12-\mathrm{e}-13$ de agosto - são gratuitas as passagens para os acionistas e convidados tanto na estrada Inglesa, como na Paulista (ALMEIDA, 1872: 2).

A publicação desse convite parece ter tido dois efeitos. De um lado, ele comunicava a abertura do tráfego da estrada de ferro em Campinas, que viria a ocorrer dia 11 de agosto de 1872. Desde início do trânsito ferroviário até a estação de Valinhos, em 31 de março do mesmo ano, não houve notícia sobre a situação da ferrovia, a não ser por anúncios de compra de materiais na estação e pela publicação dos horários dos trens no trecho já em funcionamento. De outro lado, o fato de o texto ser claramente direcionado àquelas pessoas que possuíam algum vínculo com a companhia permite pensá-lo como representação de uma das características mais marcantes do transporte ferroviário, a delimitação social dos espaços a serem ocupados pela Companhia Paulista, uma vez que é direcionado especificamente aos acionistas, para a viagem de inauguração. O fato de a companhia se utilizar do meio de comunicação com acesso ao público, e mesmo assim marcar fortemente a quem ele se destinava, parece deixar claro que alguns eram merecedores dos benefícios concedidos, no caso os associados, tendo em vista que foram eles que propiciaram a vinda daquela melhoria à cidade.

Na edição de 4 de agosto, a Gazeta de Campinas publica um artigo contendo uma mostra das imagens evocadas pela chegada da ferrovia no artigo intitulado "A propósito da estrada de ferro", cuja autoria é identificada apenas pelas iniciais “A. B.”. 4

Para o autor, organização da companhia e a construção da estrada de ferro em nível local pareciam representativos das maiores aspirações da nação e da força da ferrovia. A locomotiva, ao "invadir o deserto" e "quebrar-lhe o silêncio", "fertilizaria terras áridas", "alegraria a solidão das florestas gigantescas (...) onde a natureza se ostenta triste pela ausência de atividade humana; aí funda núcleos de população, anima o trabalho, lança o gérmen da civilização" (A. B., 1872: 1). As metáforas utilizadas pelo autor, - a

\footnotetext{
${ }^{4}$ Supõe-se que o autor "A. B." seja "A. B. de Cerqueira Cezar", identificado como um vereador de Campinas em Santos (1872b: 2-3).
} 
ideia da ferrovia como civilizatória e a da maquinaria, em oposição à natureza - foram algumas das imagens mais bem exploradas na edição do dia da inauguração da linha férrea, amplamente difundidas em quase todos os textos sobre o tema nesse período.

A edição do dia 11 da Gazeta de Campinas foi preparada antes da inauguração e se ocupava, sobretudo, em louvar o empreendimento da Companhia Paulista e em evidenciar sua importância para a cidade, tendo Francisco Quirino dos Santos ${ }^{5}$ como autor dos principais artigos. Naquela edição, Quirino afirmava que Campinas vestia-se "de galas" e que a "chama das grandes emoções passeava em todos os semblantes", pois "vai dar-se neste dia 11 de agosto o acontecimento que prende a ansiada expectativa de todos". Expressões como "expansões incomparáveis", "prosperidade" e "aurora para o futuro" (SANTOS, 1872a: 2) eram utilizadas para designar a chegada da ferrovia e exprimiam o entusiasmo e a expectativa gerada pelas mudanças profundas que ela trouxesse à cidade, constituindo-se um nítido símbolo de progresso, modernização e modernidade.

Não se pode deixar de notar a apologia que Francisco Quirino faz aos valores do trabalho que, segundo ele, teriam sido os responsáveis pelo advento do progresso, com a chegada da ferrovia à cidade: “O trabalho é uma iniciação (...) é uma prece! (...) todos os princípios de regeneração social vêm paralelos daquele foco esplêndido" (SANTOS, 1872a: 2).

Dessa forma, o trabalho, sob a ótica de Francisco Quirino, ganhava conotações místicas e era imbuído da capacidade de promover transformações profundas nos indivíduos, funcionando como "regenerador social". O trabalho foi personificado naqueles que foram considerados responsáveis por trazer a ferrovia à cidade, Saldanha Marinho e Falcão Filho: "Um teve o pensamento, o outro foi o executor da obra grandiosa que vai derramar entre nós os benefícios da civilização" (SANTOS, 1872a: 2). Para Cunha, "havia realmente uma nova fé conduzindo a atuação de líderes e de intelectuais, norteando seus discursos, a fé na capacidade humana no controle de seu destino" (2010: 29).

Joaquim Saldanha Marinho foi o presidente da província que assumira o governo em 24 de outubro de 1867, no lugar de Tavares Bastos, antecessor duramente criticado pela imprensa da época exatamente por não ter dado a devida atenção ao empreendimento

\footnotetext{
${ }^{5}$ Advogado e jornalista republicano, foi fundador da Gazeta de Campinas, o primeiro jornal da cidade.
} 
ferroviário e por sua responsabilidade nas provações de ordem material pelas quais passava São Paulo.

Por isso que, quando se tem a informação sobre a substituição do presidente da província, o Correio Paulistano publicou com exultação:

Parabéns aos paulistas! O governo imperial ouviu, finalmente, os reclamos da opinião pública e livrou a província do algoz que nos vitimava a todos. (...) O violador das leis, aquele que fazia timbre vilipendiar a dignidade da província por todos os modos, deixa-nos e vai-se para bem longe. (...) A demissão do sr. Tavares Bastos é risonho augúrio de melhores dias (CORREIO PAULISTANO apud DEBES, 1968: 79-80).

Percebe-se, nesse momento, a importância que a questão ganhava na imprensa, e as relações políticas que suscitava, evidenciando-se as posições adotadas pelo jornal sobre a questão, que expressavam as necessidades e anseios de diversos grupos locais.

Após assumir o cargo, Saldanha Marinho empreendeu algumas viagens: a primeira foi a Santos - em 20 de novembro - e a segunda a Campinas, para onde partiu em 14 de dezembro de 1867.

A viagem a Campinas tinha como finalidade, segundo o Correio Paulistano, realizar uma reunião para "dar corpo e realização ao projeto do prolongamento da estrada de ferro até aquele ponto" (CORREIO PAULISTANO apud DEBES, 1968: 81-82). Célio Debes se refere a artigo publicado na ocasião, nesse jornal, na seção "A pedido", o qual sustentava que "ressurge a empresa grandiosa; e como impulsor amestrado e seguro, imprime-lhe prestígio e resolução o ilustre presidente da província, prestes a chegar a esta cidade" (CORREIO PAULISTANO apud DEBES, 1968: 82).

$\mathrm{Na}$ reunião com os cidadãos de Campinas e de outras localidades da província, Saldanha Marinho falou sobre "o meio mais cômodo e econômico de levantar o capital necessário" (DEBES, 1968: 82) e as possibilidades existentes nesse sentido, de buscá-lo entre os paulistas ou no estrangeiro. Trataram das plantas levantadas, escolhendo, por fim, aquela que seria executada. Constituir-se-ia - isso era seguro - "uma companhia com o capital de 5 mil contos de réis, dividido em ações de $200 \$ 000$ réis, 'ou em equivalente esterlino"” (CORREIO PAULISTANO apud DEBES, 1968: 82).

À época da viagem de Saldanha Marinho a Campinas, a diretoria da São Paulo Railway já havia deixado claro que não tinha mais intenção em prolongar seus trilhos de 
Jundiaí até Campinas. Com isso, o presidente da província conclamava os paulistas para executarem a obra, especialmente a elite cafeicultora, cujo interesse na estrada de ferro repousava também no fato de que ela permitiria melhor escoamento de sua produção. Como afirmaria ele, posteriormente: "Fiz o que me cumpria. Apelei para os paulistas. Não lhes faltava nem vontade nem possibilidades e, portanto, não poderia ser inútil o apelo". 6

Até Jundiaí a comitiva viajou pela estrada de ferro e, de lá até Campinas, prosseguiu pela estrada de rodagem. Esta estava

em tão mau estado de trânsito, que entre Rocinha e os Dois Córregos, a diligencia em que viajavam o exm. Barão de limeira, José Maria de Andrade, engenheiro N. Bennaton, dr. Antonio Aguiar de Barros, e Dr. Henrique Cezar Muzio, quebrou-se com estrépito ficando inutilizada para continuar a viagem até Campinas (CORREIO PAULISTANO apud DEBES, 1968: 83-84).

Em 16 de Dezembro de 1867 ocorreu na Câmara Municipal de Campinas a assembleia dos interessados no prolongamento da estrada de ferro, na qual Saldanha Marinho dirigiu-se aos presentes, dizendo:

que sua estada em Campinas não era um passeio rodeado de ostentação e vaidade; que delegado do Governo Imperial ali se tinha dirigido só e unicamente para tratar de um dos mais vitais interesses da província, pois que assim considerava o prolongamento da estrada de ferro até Campinas (CORREIO PAULISTANO apud DEBES, 1968: 85-87).

No discurso, o presidente da província buscou demonstrar as vantagens que adviriam para a cafeicultura da vinda da ferrovia, especialmente no que se referia à diminuição do custo nos transportes. O resultado da assembleia foi positivo, pois nesse mesmo dia foram subscritas cinco mil ações, totalizando mais de um quinto do capital necessário à empresa. Formaram-se, ainda, comissões com a incumbência de divulgar a iniciativa e reunir novos acionistas. ${ }^{7}$

\footnotetext{
${ }^{6}$ RELATÓRIO apud DEBES, 1968: 83.

${ }^{7}$ Observar o quadro formado por essas comissões permite um verdadeiro mapeamento das cidades em que os produtores de café tinham grande influência. Segundo o jornal Diário de São Paulo, de 21 de dezembro de 1867, as cidades das comissões foram as seguintes: São Paulo, Campinas, Amparo, Mogi-Mirim,
} 
A 30 de Janeiro de 1868, a Companhia Paulista se consolidou e elegeu sua primeira diretoria, tendo como primeiro presidente aquele que, ao lado de Saldanha Marinho, seria considerado um dos responsáveis pelo empreendimento: Clemente Falcão de Souza Filho. Depois de formada, a Companhia passou por um período de organização em sua estrutura, tendo o governo imperial concedido a autorização oficial para funcionar apenas em 28 de novembro de 1869, pelo decreto 4.283 (RELATÓRIO, 1869).

Como se verifica, desde antes da inauguração da estrada de ferro até Campinas, Saldanha Marinho e Falcão Filho eram vistos como empreendedores cujos papéis seriam fundamentais na ruptura com o passado que a ferrovia proporcionaria e, por isso, mereceriam ser homenageados com todo entusiasmo quando da abertura do tráfego.

Isso pode ser verificado no discurso de Falcão Filho durante a cerimônia de inauguração, no qual este demonstra a ânsia por mudanças que fossem além das transformações materiais e atingissem profundamente a vida das pessoas. Para ele "o aparecimento, a vida, as tradições da Companhia Paulista querem dizer uma regeneração, e as regenerações de hábitos antigos (...). Seu discurso é um louvor à iniciativa paulista, à ideia, ao capital e ao trabalho (...)" (SANTOS, 1872b: 2-3)

A preparação na cidade para a recepção da ferrovia incluiu uma série de atividades, por três dias, bem como os "brindes" preparados pelas "várias classes" da sociedade local. Assim, no dia da inauguração houve uma festa ao progresso, em que a cidade "vestiu-se de galas", em que a "chama das grandes emoções passeou em todos os semblantes", como fez questão de fixar a Gazeta de Campinas, pelas palavras de Francisco Quirino dos Santos (1872a: 2).

\section{A narrativa da inauguração}

A narrativa dos festejos aparece apenas em 18 de agosto e foi construída de modo a mostrar que as emoções daquele evento ficariam vivas na memória de todos que presenciaram a inauguração:

Enfim temos a nossa estrada de ferro. (...) Entusiasmo, júbilo, frenesi das expansões incomparáveis. O dia 11 - a ansiada aurora do nosso futuro - abriuse afinal nadando em ondas de harmonias, num concerto mágico de todos os

Limeira, Rio Claro, Constituição (Piracicaba), Capivari, Belém do Descalvado, Pirassununga, São Carlos do Pinhal, Araraquara e Santos (apud DEBES, 1968: 129). 
bulícios que o prazer derrama quando vem sinceramente do peito (SANTOS, 1872b: 2-3).

O ponto alto do evento foi, obviamente, a chegada do comboio:

às três horas e meia quando um estremecimento estranho veio eletrizar em todos os sentidos aquela reunião enorme: ouvia-se longínquo um rugido estridente e os ecos repercutiam pelas nossas belas campinas o férreo galopar de misterioso hipogrifo. O que se passou nesse instante foi uma cousa que não se diz: sonha-se ou vê-se (SANTOS, 1872b: 2-3).

Para o jornal, a chegada do trem

era a apoteose majestosa do gênio do homem identificado com o símbolo das grandes invenções modernas, foi um espetáculo maravilhoso! E continua: Entusiasmo assim não se prepara: nasce de si mesmo, como lava no seio dos vulcões para esbrasear a face das montanhas e derramar o calor e o brilho pela atmosfera incendiada (SANTOS, 1872b: 2-3).

Chegaram a Campinas:

duas locomotivas galhardamente enfeitadas com topes, fitas, laços e bandeiras abriam caminho puxando 19 vagões em que vinham os dois grandes vultos do dia - Saldanha Marinho e Falcão Filho (...) e vinham mais o resto do diretório desta e inúmeros acionistas e convidados, entre os quase o presidente desta província, o chefe de polícia, etc. (SANTOS, 1872b: 2-3).

Tendo parado o trem, Saldanha Marinho e Falcão Filho foram recepcionados pela Câmara Municipal, outras autoridades locais, e também pela "multidão inteira que não parava de vitoriar". Seguiu-se a isso a bênção da estação ferroviária pelo sacerdote V. Pires da Motta e uma série de discursos, iniciada por Falcão Filho, referido acima. Sucederam-no o "Dr. V. M. de Paula Lacerda (...) recordando nomes a quem a ciência deve os seus mais felizes e mais firmes passos". Campos Sales, à época deputado provincial, discursou sobre a "iniciativa individual que gerou o fecundo gérmen da atividade industrial" em Campinas e ofereceu, em nome "dos homens de letras", a Saldanha Marinho, seu retrato a óleo, "pedindo licença para ser ele colocado em uma das 
salas da estação". Francisco Quirino dos Santos comemorou o "fato que prendia todas as atenções" e, tal como Campos Salles e também em nome dos homens de letras da cidade, ofereceu um quadro a óleo a Falcão Filho, para ser colocado em "posição paralela ao de Saldanha Marinho na Sala onde esse fosse colocado". Por fim, "declarou que estava ali a representar a imprensa" e recitou os versos sob o título de "Inauguração". Esses versos, que aparecem em outra parte do jornal, sob o título de "Canto inaugural", foram oferecidos a Saldanha Marinho e Falcão Filho (SANTOS, 1872b: 2-3).

O tom exaltado do "canto" em homenagem à inauguração expressava a carga simbólica que o advento ferroviário adquiriu na cidade. Percebe-se a presença das analogias com o mundo natural e a ideia de que o homem estava destinado a aprimorarse, a progredir, a partir do fervor de seus sonhos e por meio de seu trabalho. Curvar-seiam humildemente à natureza o chão, o mar, o ar e mesmo os raios, ante o "gênio audaz" da humanidade. As "rodas do progresso", em um "giro louco e aflito", trouxeram a ferrovia. Com elas deveriam acabar as distâncias, as nações seriam aproximadas e o mundo todo seria um lar, se transformaria em família o que antes era apenas o povo (SANTOS, 1872b: 2-3).

Após essas homenagens a Saldanha Marinho e Falcão Filho, sucederam-se outras das diversas comissões da cidade, cantos, discursos, presentes e orações, tudo em louvor à obra e àqueles que possibilitaram sua existência. E para tal festividade a cidade havia de ser enfeitada e iluminada, o que acabou por dar-lhe feições novas, segundo as percepções de Francisco Quirino: “As ruas da cidade haviam-se iluminado em toda sua extensão. Era maravilhoso de ver-se a perspectiva esplendente da nossa Campinas" (SANTOS, 1872b: 2-3).

A iluminação e os enfeites davam à cidade novos contornos e perspectivas, mas, apesar da admiração que o jornalista mostrava pelas belas feições que Campinas adquirira, para ele a estação ferroviária e as estruturas adjacentes eram a grande atração e ganhavam destaque aos olhos do público: "as pilastras da estação estavam decoradas com um letreiro cada uma: lendo-se nelas, como num troféu, o nome de todas as estações da linha férrea a começar de Santos" (SANTOS, 1872b: 2-3).

O litógrafo Jules Martin retratou o momento da chegada do trem na inauguração, como se observa pelas imagens 3 e 4 . Por meio de análises iconográficas e mesmo da observação in loco, pode-se concluir que o artista, ao realizar a pintura, estava posicionado atrás da estação, encontrando-se o trem entre esta e o observador. 


\section{Imagem 3}

Inauguração da ferrovia até Campinas.

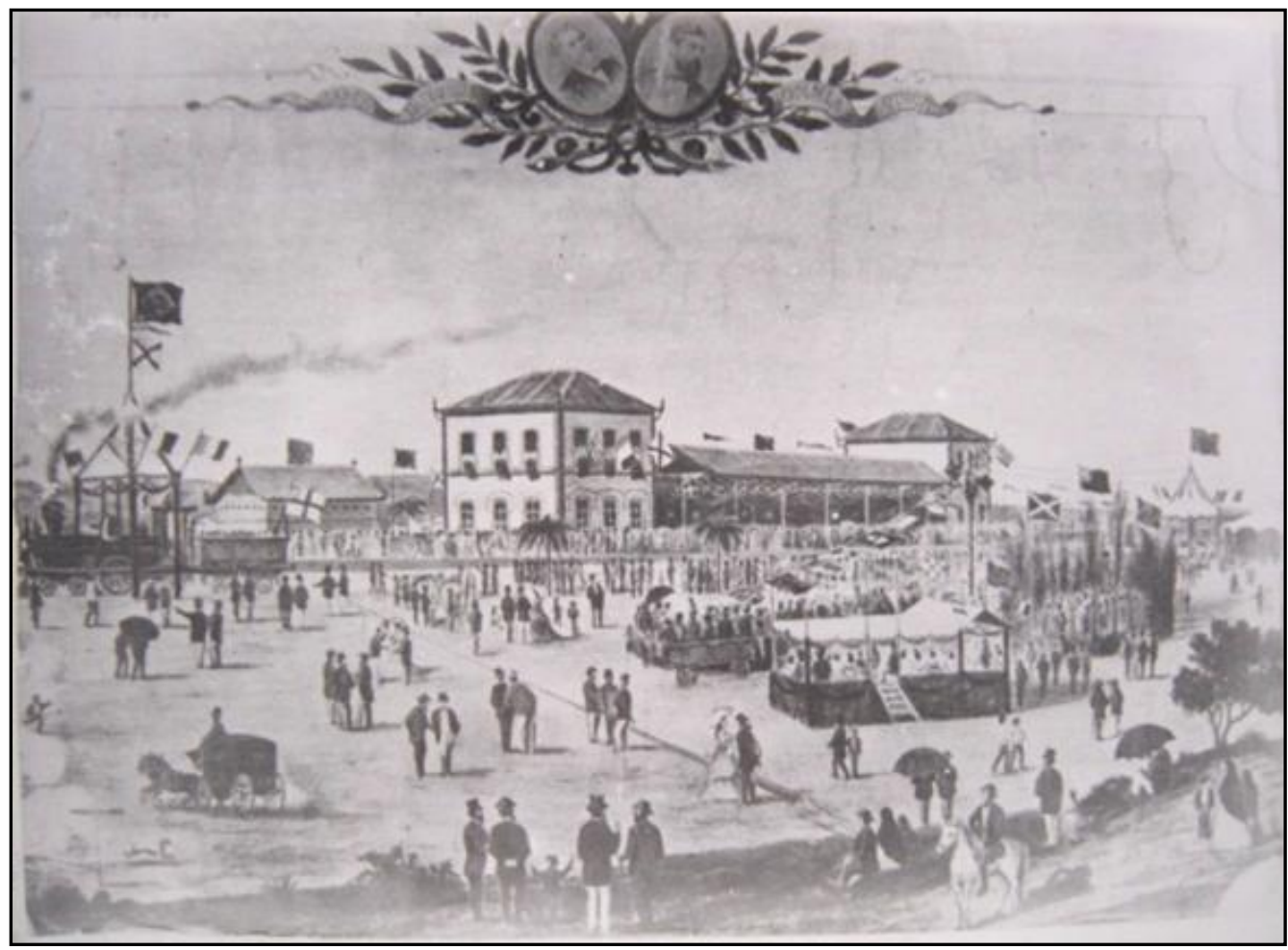

Fonte: MARTIN, 1872.

Museu da Cidade de Campinas

\section{Imagem 4}

Inauguração da ferrovia até Campinas.

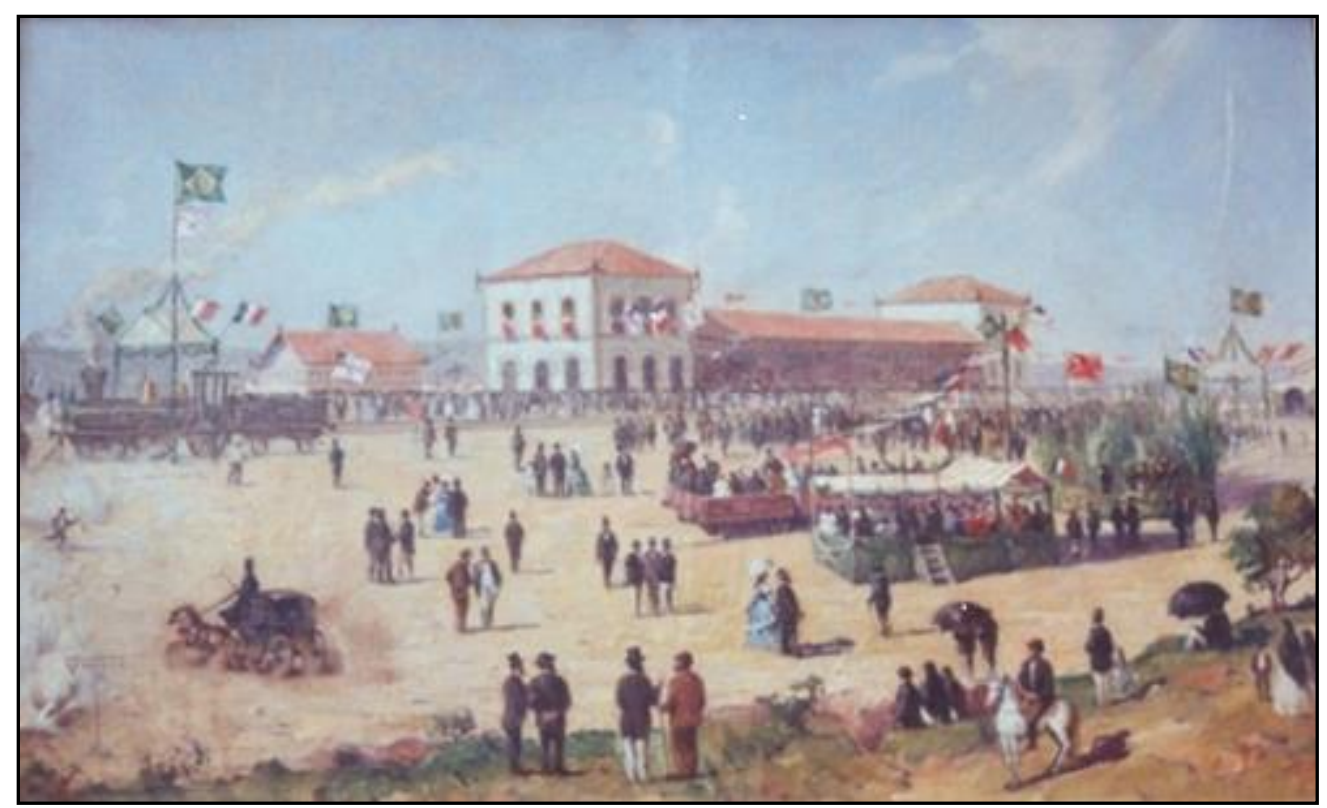

Fonte: MARTIN, 1872.

Museu da Imagem e do Som de Campinas. 
Ao promover o trabalho artístico de Jules Martin, a Gazeta de Campinas mostrava que ele também serviria para preservar na memória aquele acontecimento, para "recordar perpetuamente aquela grande festa que jamais se deve varrer da memória de todos os bons brasileiros e especialmente os filhos desta deliciosa Campinas" (VISTA, 1872: 2).

Nas imagens acima, é possível visualizar uma carruagem apressada à esquerda e abaixo, à direita, coretos e palanques em que estão muitas pessoas reunidas. O edifício da estação e os coretos estão todos adornados com laços e bandeiras dentre as quais se podem identificar a do império brasileiro, outras que parece ser da França, da Inglaterra, dentre outras. Alguns espectadores são retratados na parte inferior da imagem, numa área que parece ser mais elevada em relação ao terreno onde a aglomeração das pessoas era maior, de onde provavelmente eles teriam uma vista melhor da chegada do trem. Na plataforma da estação e ao longo da linha uma multidão é representada como que a esperar a chegada do comboio, vindo de Jundiaí.

As imagens 3 e 4, apesar de representarem a mesma cena, são diferentes se observadas com mais cuidado, especialmente no que se refere ao fato de a imagem 3 mostrar uma quantidade de pessoas no evento muito maior do que a imagem 4 , além do fato de que cada uma das imagens possui algumas cenas distintas. $\mathrm{Na}$ imagem 3 , junto à borda superior, nota-se o retrato de duas pessoas, possivelmente Saldanha Marinho e Falcão Filho, enfeitados com ramos e frutos de café e a faixa contendo a frase atribuída a Virgílio "Labor omnia vicit improbus", que poderia ser traduzida como "o trabalho persistente vence tudo", de modo que fica evidente, mais uma vez, a ideia da iniciativa e do trabalho como provedores daquilo que se desejava, no caso a ferrovia.

Segundo Francisco Quirino dos Santos “eram mais de 11 horas [da noite] quando a população começou a rarear”. Os dois dias seguintes também tiveram uma programação voltada à comemoração pela chegada da ferrovia. $\mathrm{O}$ dia 12 iniciou com um Te-Deum Laudanus na Igreja Matriz da Conceição e, por volta das 2 horas da tarde, "reuniu-se a Câmara Municipal em seu paço" e lá houve uma cerimônia em que foi lembrada a figura de Diogo Antônio Feijó, tendo Saldanha Marinho lido “um ofício do Dr. J. A. Pinto Junior, oferecendo àquela corporação o retrato em relevo, os cabelos n'um quadro e vários autógrafos do venerado paulista". À noite realizou-se um baile no "teatro de São Carlos, cujo edifício estava todo iluminado, sendo a gás algumas divisões do frontispício, o que dava-lhe uma elegante e desusada aparência realçada pela sua forma artística". Francisco Quirino não deixou de salientar que o baile chamou a atenção pelo público que atraiu, “mais de 600 pessoas", bem como pela "imponente concorrência e pelas custosas, 
riquíssimas e elegantes toaletes" das moças e senhoras de Campinas e de cidade vizinhas. A festa prolongou-se "até quase 4 horas da madrugada" (SANTOS, 1872b: 2-3).

$\mathrm{O}$ dia 13 teve como destaque um jantar promovido em homenagem à Saldanha Marinho, o qual estava cercado de pessoas das mais diferentes atividades:

À volta do benemérito cidadão juntava-se numa sociedade fervente de fé e de crenças nobre nos destinos de seu país, o conjunto completo das diversas classes de homens assinaladas pelo verdadeiro modo de conhecê-las, isto é, as profissões. Ali estava o lavrador encanecido ao pé do moço literato, o advogado em face do comerciante; o médico junto do industrial, etc., etc. (SANTOS, 1872c: 1).

O encontro foi tratado como um "jantar político", por ter sido "oferecido pelos republicanos" da cidade. A partir das cinco horas da tarde houve uma série de brindes e discursos, quando "se abriu o festim":

E cada uma saúde [brinde] era uma alocução cheia de vida, esplêndida de esperança pelos princípios livres tais como eles se inscrevem à face deste século que é uma orla d'oiro na vertiginosa bandeira do progresso. (...) Havia como que um ambiente de luz estranha naquela sala a circundar as frontes a todos os conjurados do pensamento e do trabalho e, portanto, a todos os sectários das reformas profundas conquistadas no seio da mesma paz, com os recursos da perseverança e da coragem (...) (SANTOS, 1872c: 1).

Projeções futuras positivas e progressistas quanto ao desenvolvimento do país são a direção tomada pelos discursos e brindes que, pela imagem construída no artigo, deveriam se estender àqueles que por elas lutassem. De forma simbólica o jantar representava aqueles que ansiavam pela ferrovia e outros melhoramentos, que lutaram para trazê-los e que agora se congratulavam mutuamente. Entretanto, em sentido inverso o artigo transparece também a quem as transformações mais favoreceriam: no jantar estavam apenas homens da alta sociedade campineira e das cidades vizinhas, excluindose a maior parte da população.

A inauguração da linha férrea ganhou destaque entre os historiadores e memorialistas de Campinas ao longo dos anos e pode ser vista como marco simbólico das transformações pela qual cidade passava, cuja percepção fica mais bem assinalada ao se 
observar a maneira como foram construídos os relatos acerca do episódio. Esse momento deveria ficar lembrado como o que iniciou um novo tempo na cidade, provocador de mudanças e transformador do cotidiano e das sensibilidades.

Mudanças essas que poderiam ser sentidas já pelos novos sons com os quais a cidade viria a conviver, pelos "rugidos estridentes", ou pela "atmosfera" que se incendiaria diariamente com o trânsito das locomotivas. É frequente nos textos o uso de metáforas da natureza para designar as cenas e as sensações que os novos eventos teriam provocado nas pessoas. O poema "A locomotiva", assinado por Thomaz Ribeiro, esta é apresentada como um "monstro de fogo", um "ígneo furacão", que "silva", "muge" e "sacode as crinas de fumo" enquanto "devora os espaços". Estão aqui presentes imagens que evocam o paralelo traçado entre a máquina e o mundo natural, animal, selvagem e também imagens contraditórias suscitadas pela novidade, de criação e destruição, o que evidencia ainda mais a força simbólica da ferrovia. Além disso, figuram imagens que evocam a monstruosidade daquilo que a "ciência", "o estudo" e o trabalho ("a lida") teriam construído, que havia de ultrapassar todos os horizontes e chegar a todos os povos para iluminar e eliminar os desertos não civilizados, com um caráter quase inevitável 162 (RIBEIRO, 1872: 1).

A força das imagens revela a expectativa quanto às transformações - positivas, aos olhos daqueles homens -, que a ferrovia traria ao futuro cidade. Mudanças essas que talvez pudessem ser sentidas também pelo número de pessoas que se dirigiu a Campinas para o evento, o que é evidenciado claramente na imagem de Jules Martin, mesmo com as variações, e marcado pelas palavras de Francisco Quirino: “desde manhã logo começara a multidão avultando pelos passeios, sôfrega, densa, flutuante, a regurgitar por todos os pontos, especialmente por ali, (...) ondas de povo afluíam pelas ruas e pelos terrenos da estação" (SANTOS, 1872b: 2-3).

O espanto decorrente do grande número de pessoas na cidade era representação recorrente nas inaugurações ferroviárias desde a implantação das primeiras estradas de ferro na Europa (Cf. HARDMAN, 1988). As impressões de Francisco Quirino dos Santos sugerem a força do impacto desencadeado pela ferrovia.

Pode-se sugerir que, em Campinas, as palavras de Francisco Quirino encontraram, naquele instante, "ressonância imediata no imaginário coletivo" (BRESCIANI, 1984/1985: 51), já que as sensações por elas evocadas seriam compartilhadas por todos que haviam passado por aquela experiência.

Como mostra Bresciani, o universo de percepção por meio de imagens 
assustadoras, poderosas em sua força, infinitas ou com seus limites velados, portentosas enfim, compõe essa nova sensibilidade no século XIX. A força dos atos inaugurais, com seu caráter revelador de coisas antes submersas, e com seu poder transformador, ficou para sempre marcada na grandeza da imagem construída pelos homens que presenciaram a imposição da máquina e se chocaram com a revelação pública das necessidades e expectativas dos homens pobres (BRESCIANI, 1984/1985: 51).

O "ato inaugural" da ferrovia em Campinas, então, também teria sido capaz de minimizar as diferenças sociais e culturais na aparência, pois o que se via era apenas a multidão, uma "aglomeração" em festa. A documentação sugere a imagem de uma festa "generalizada", em que a cidade comemorava um acontecimento que viria transformar a vida de todos, mesmo daqueles que não almejassem ou simplesmente estivessem alheios a tais mudanças.

Percebe-se, então, a partir do exemplo examinado, que o fenômeno ferroviário no Brasil é possuidor de uma carga simbólica de progresso e civilização, de modernidade. O preparo de Campinas para o dia da inauguração denota a busca por esses valores, cuja maior expressão era a ferrovia que trazia para aqueles homens a possibilidade concreta de alcançá-los.

\section{Considerações finais}

Em estudos sobre cidades, sobre arquitetura ou especificamente sobre transportes, as ferrovias figuram como provocadoras de profundas transformações no que se refere ao crescimento populacional das áreas urbanas, no estímulo à circulação de pessoas e mercadorias e na velocidade dos transportes, entre outras questões. Além disso, neste processo, as transformações da estrutura das cidades ocorreram paralelamente e com influência mútua sobre as mudanças nas percepções do homem sobre a própria realidade (BENEVOLO, 1989; CASTRO, 1993; LESSA, 1993; HARDMAN, 1988; SCHIVELBUSH, 1986).

Portanto, é possível dizer também que a introdução dessa inovação tecnológica no cotidiano contribuiu para alterar as sensibilidades e temporalidades do homem e sobre o seu meio. De modo geral, os estudiosos parecem tratar como um ideal compartilhado a 
vontade de transformar, sempre com perspectivas positivas para seu futuro, a sociedade e o mundo.

Como mostra Castro (1993: 02), tais mudanças "resultariam em uma transformação substancial no modo de vida das pessoas, seus relacionamentos sociais e com a natureza e na própria concepção de mundo em que se vivia”. Nesse sentido, para Lessa (1993: 12-14), a partir do aparecimento de novos artefatos industriais, somados a outras transformações, houve um grande impacto na mentalidade dos homens que vivenciaram aquele momento de transição nos modos de sentir, de viver.

Diversas inovações no século XIX tiveram papel fundamental para tais mudanças, dentre as quais ganham destaque as ferrovias, cujas estruturas alteraram profundamente o meio em que viviam os homens, suas sensações e percepções sobre a realidade que os cercava.

As transformações de ordem material e tecnológica, então, afetaram diversos aspectos da vida cotidiana, o que parece ficar mais nítido ao se estudar como as cidades foram transformadas, desde suas mudanças estruturais até os novos comportamentos sociais e novas visões de mundo que foram engendrados em seus habitantes. Nos centros urbanos é possível encontrar com mais força a ideia de que as transformações atingiram os hábitos, as convicções, as percepções e até os reflexos instintivos das pessoas. Além disso, mudaram também as relações sociais, que se estreitaram à medida que as transformações atingiram o cotidiano das pessoas (LESSA, 1993; CASTRO, 1993; HARDMAN, 1988; SCHIEVELBUSH, 1986).

$\mathrm{Na}$ historiografia, as interpretações são múltiplas na tentativa de elucidar, especificamente, como o Brasil participou das diversas transformações no século XIX (COSTA: 1979; HARDMAN: 1988; LESSA, 1993; CASTRO, 1993). Interpretações mais amplas, referindo-se à Europa ou à América Latina, por exemplo, permitem fazer um contraponto sobre tais mudanças no Brasil (GORELIK, 1999; HOBSBAWM, 1996; SCHIEVELBUSH, 1986).

A questão central no debate é como o modelo foi assimilado sem se ter sido, porém, uma simples cópia ou transferência de modelos, uma vez que se constituiu um processo mais complexo: ideias como a de progresso, civilização e modernidade seriam concebidas não como pertencentes a este ou àquele país, e sim seriam ideais internacionalizáveis. Era comum, então, que cada lugar, ao defender tais ideais, o fizesse de acordo com suas possibilidades e necessidades. 
Assim, os produtos e estruturas industriais, como as ferrovias, ao serem importados pelo Brasil, foram tomados como símbolos desses valores almejados, cujos referenciais eram europeus, o que se evidencia pela documentação produzida no período. Isso não significa que os objetos que evocavam tais valores no Brasil tivessem o mesmo significado para a Europa. Ao contrário, poderiam assumir representações e simbologias específicas em cada lugar.

Não eram, então, apenas das novidades em si que o Brasil se apropriava e utilizava, mas também da carga simbólica desses artefatos industriais, dos quais destacase a ferrovia, como se verifica pelo caso de Campinas. É por isso, portanto, que se pode afirmar que a chegada da ferrovia nessa cidade estava ligada aos anseios por progresso, industrialização, modernização e modernidade.

\section{Fontes}

A. B. (1872). A propósito da estrada de ferro. Gazeta de Notícias, 4 de agosto, p. 1. ALMEIDA, Francisco Martins de (1872). Companhia Paulista. Gazeta de Campinas, $1^{\circ}$ de agosto, p. 2.

ANÚNCIO da casa comercial "Ferreira Novo \& Filho" (1872). Gazeta de Notícias, 28 de abril, p. 4.

COMPANHIA PAULISTA (1872). Gazeta de Campinas, $1^{\circ}$ de agosto, p. 2.

HALLE, J. Van (1872). Impressões de minha viagem ao Brasil - Progressus - Indústria - Veritas: Viagem de São Paulo a Campinas. Gazeta de Campinas, 6 de janeiro, p. 2.

MARTIN, Jules (1872). Inauguração da ferrovia até Campinas. Litografia. Museu da Cidade de Campinas.

MARTIN, Jules (1872). Inauguração da ferrovia até Campinas. Litografia. Museu da Imagem e do Som de Campinas.

RIBEIRO, Thomaz (1872). A locomotiva. Gazeta de Campinas, 11 de agosto, p. 1.

SANTOS, Francisco Quirino dos (1872a). A iniciação. Gazeta de Campinas, 11 de agosto, p. 2.

SANTOS, Francisco Quirino dos (1872b). A estrada de ferro - Discurso da inauguração da estrada de ferro da Companhia Paulista, recitado pelo presidente desta, Dr. Clemente Falcão de Souza Filho - Canto inaugural oferecido a Saldanha Marinho e Falcão Filho. Gazeta de Campinas, 18 de agosto, p. 2-3.

SANTOS, Francisco Quirino dos (1872c). Jantar político. Gazeta de Campinas, 22 de agosto, p.1.

RELATÓRIO da Companhia Paulista para sessão da Assembleia Geral de 26 de setembro de 1869 (1869). São Paulo: Correio Paulistano.

VISTA da estação (1872). Gazeta de Campinas, 5 de setembro, p. 2. 


\section{Referências Bibliográficas}

BENEVOLO, Leonardo (1989). História da arquitetura moderna. Trad. de Ana M. Goldberger. São Paulo: Perspectiva.

(1994). Origens da urbanística moderna. Trad. de Conceição Jardim e Eduardo L. Nogueira. Lisboa: Presença.

BERMAN, Marshall (1982). Tudo que é sólido se dissolve no ar: a aventura da modernidade. Trad. de Ana Tello. Lisboa: Edições 70.

BRESCIANI, Maria Stella M (1984-1985). Metrópoles: as faces do monstro urbano. Revista Brasileira de História. São Paulo, vol. 5, n. 8/9, pp. 35-68.

CASTRO, Maria Inês Malta (1993). O preço do progresso: a construção da Estrada de Ferro Noroeste do Brasil (1905-1914). Dissertação (Mestrado em História). Universidade Estadual de Campinas, Campinas, São Paulo.

COSTA, Emília Viotti da (1979). Da monarquia à república: momentos decisivos. São Paulo: Ciências Humana Ltda.

CUNHA, Cinthia da Silva (2010). As exposições provinciais do Império: a Bahia e as exposições universais (1866-1888). Dissertação (Mestrado em História). Universidade Federal da Bahia, Salvador.

DEBES, Célio (1968). A caminho do Oeste: história da Cia. Paulista de estradas de ferro. São Paulo: s.e.

FURTADO, Fernando F. F. (1998). Trem e cinema: Buster Keaton on the railroad. São Paulo: Cone Sul.

GORELIK, Adrián (1999). O moderno em debate: cidade, modernidade e modernização. In: MIRANDA, Wander Melo (Org.). Narrativas da modernidade. Belo Horizonte: Autêntica.

HARDMAN, Francisco F. (1988). Trem fantasma: a modernidade na selva. São Paulo: Companhia das Letras.

HOBSBAWM, Eric J. (1996). A era do capital (1848-1875). Trad. de M. T. L. Teixeira e M. Penchel. São Paulo: Paz e Terra.

KUMAR, K. (1997). Da sociedade pós-industrial à pós-moderna: novas teorias sobre o mundo contemporâneo. Trad. de Ruy Jungmann. Rio de Janeiro: Jorge Zahar.

GRAHAM, Richard (1973). A Grã-Bretanha e o início da modernização no Brasil (18501914). Trad. de Roberto Machado de Almeida. São Paulo: Brasiliense.

LAPA, José Roberto do Amaral (1996). A cidade: os cantos e os antros. São Paulo: EDUSP.

LE GOFF, Jacques (1990). Trad. de Bernardo Leitão. História e Memória. Campinas: Unicamp.

LESSA, Simone Narciso (1993). Trem de ferro: cosmopolitismo no sertão. Dissertação (Mestrado em História). Universidade Estadual de Campinas, Campinas, São Paulo.

MATTOON, Robert H. (1971). The Cia. Paulista de Estradas de ferro (1868-1900): a local railway enterprise in São Paulo. Tese (Doutorado em Economia). Yale University, New Haven, Connecticut.

POZZER, Guilherme (2007). A antiga estação da Companhia Paulista em Campinas: estrutura simbólica transformadora da cidade (1872-2002). Dissertação (Mestrado em História). Universidade Estadual de Campinas, Campinas, São Paulo.

SCHIVELBUSCH, Wolfgang (1986). The railway journey: the industrialization of time and space in XIX century. Berkeley: The University of California Press. 
SINGER, Paul. De dependência em dependência: consentida, tolerada e desejada. Estudos Avançados, São Paulo, v. 12, n. 33, p. 119-130, Aug. 1998.

Artigo recebido em 29 de outubro de 2014.

Aprovado em 15 de março de 2015.

DOI: 10.12957/intellectus.2015.18802 